\title{
POLITICAS DE SUELO INDUSTRIAL EN ÁLAVA
}

\author{
Marisol Esteban Galarza \\ Departamento de Economía Aplicada. Universidad del País Vasco \\ Irantzu Álvarez González \\ Departamento de Expresión Gráfica y Proyectos de Ingeniería. Universidad del País Vasco \\ $M^{\mathrm{a}}$ Concepción Torres Enjuto \\ Departamento de Geografía, Prehistoria y Arqueología. Universidad del País Vasco
}

\section{RESUMEN}

En este artículo son analizadas las políticas de suelo industrial en Álava, uno de los tres territorios históricos o provincias), junto con Vizcaya y Guipúzcoa, que integra la Comunidad Autónoma del País Vasco (CAPV en adelante). En un primer apartado exponemos los planteamientos teóricos actuales que inspiran el diseño de las políticas en materia de suelo industrial y posteriormente valoramos las actuaciones y los resultados de los diferentes organismos que gestionan este tipo de suelo en Álava. Finalmente, avanzamos los resultados preliminares obtenidos mediante el SIG Alavamap.

Palabras clave: suelo industrial, Álava, SIG, Alavamap, País Vasco.

\section{ABSTRACT}

This paper analyzes the industrial lands policies in the province of Alava (Basque Country). Firstly, we describe the current theoretical approaches that inspire the design of policies for industrial land and secondly we analyze the programs and results of the organizations who manage the land used for business areas and industrial parks in Alava. Finally, we analyze de results obtained through the Alavamap GIS.

Key words: industrial land, Alava, GIS, Alavamap, Basque Country.

Fecha de recepción: julio 2010.

Fecha de aceptación: febrero 2012. 


\section{INTRODUCCIÓN}

La promoción de suelo para actividades económicas (industriales, logísticas, comerciales y de servicios) es una actuación ya clásica dentro de las políticas de desarrollo socio-económico de una región por parte de los organismos públicos desde la década de 1950 en Europa. En este artículo nos referiremos al suelo industrial de modo preferente, dada la relevancia de la actividad fabril (34,5\% del VAB sin construcción en 2008) en Álava después de los servicios $(56 \%)$ y por su estrecha relación con el sector terciario. La participación del VAB de la industria en Álava es superior a la del País Vasco $(27,9 \%$ en ese mismo año) según datos del Eustat. En el País Vasco las actuaciones orientadas a la oferta de suelo industrial tienen su origen desde la transferencia de competencias autonómicas en 1982 con la SPRI (Sociedad para la Promoción y Reconversión Industrial, S.A., Agencia de Desarrollo del País Vasco creada en 1981 y cuya denominación actual mantiene el acrónimo inicial de SPRI, pero es denominada «Sociedad para la Transformación Competitiva»). A pesar de haber habido casi treinta años de experiencia en la gestión del suelo las responsabilidades siguen estando fragmentadas en Ayuntamientos, Diputaciones y Gobierno Vasco, lo cual dificulta la obtención de una visión global acerca de esta materia. Asimismo, la orografía accidentada y la mezcla de usos del suelo (industrial, infraestructuras y residencial) heredada desde hace más de un siglo en algunas comarcas complica aún más esta panorámica general. El suelo industrial disponible (calificado y urbanizado) es un recurso escaso y un aspecto básico para la planificación del futuro suelo urbanizable. La gestión sostenible del suelo, consolidado y previsto, puede ser mejorada notablemente mediante una herramienta flexible y común para las diferentes instituciones: un Sistema de Información Geográfica (SIG).

En este artículo nos proponemos analizar las políticas de suelo industrial de Álava. En primer lugar, apuntamos los factores relativos a la coyuntura económica y señalamos los planteamientos teóricos que inspiran el diseño de las políticas de suelo. A continuación, repasamos las políticas de suelo implementadas en Álava y acabaremos analizando los resultados iniciales obtenidos a través del SIG Alavamap. ${ }^{1}$

\section{CONTEXTO TEÓRICO SOBRE LAS POLÍTICAS DE SUELO}

En la actualidad podríamos destacar tres factores relativos al entorno económico que influyen directamente en la actividad empresarial y en las políticas de suelo:

- La crisis económica, vigente desde el otoño de 2008 y reconocida desde enero de 2009 (Gual, 2009), que ha reducido algunos planes de expansión de empresas existentes, ha limitado las plantillas, la actividad productiva y ha supuesto una caída abrupta en la aparición de empresas, con la consiguiente caída de demanda de suelo.

- El proceso de globalización creciente, que va asimilando a países cada vez más distantes. Este proceso propicia la competencia entre regiones muy lejanas entre sí y genera una presión competitiva en aumento, que obliga a las empresas a la expansión

1 Siguiendo las recomendaciones de la Real Academia Española hemos escrito los topónimos en español al ser éste el idioma en el que está redactado el artículo y no tratarse dicho artículo de un documento oficial (B.O.E., por ejemplo) en cuyo caso habría que utilizar el nombre oficial aprobado por las Cortes españolas y que para cada uno de los tres territorios históricos es Araba/Álava, Bizkaia y Gipuzkoa. 
exterior y a una apuesta por la innovación. Como consecuencia de la reorganización espacial de las tareas de la empresa se generan demandas de suelo muy sofisticado y dimensión limitada en el País Vasco y suelo en el extranjero (de oficinas y para establecimientos productivos).

- Sofisticación de políticas de desarrollo regional. La complejidad del entorno en el que tienen que operar las empresas ha impulsado una mejor articulación y renovación de las políticas de innovación desde las regiones y a escala europea. En lo que se refiere a la oferta de suelo hay que destacar la amplia variedad de formatos, calidades, precios y condiciones que ofrecen desde las políticas de impulso a la actividad económica.

Una vez citados estos factores recordaremos algunas características del suelo industrial, para contextualizar las actuaciones públicas (Méndez, 1997):

- El suelo industrial es un bien escaso, que suele estar en competencia con otros usos, ya sean rurales, residenciales, terciarios, o de equipamiento, y que además puede ser incompatible con algunos de ellos, por ejemplo con uso residencial (de calidad). Por tanto, la localización de usos industriales tiene una relevancia destacada a nivel intraurbano y en la organización territorial de la región. En la ciudad por influir en la estructura interna del núcleo urbano y en la región por desarrollar un papel notorio en el equilibrio territorial en la distribución de población y actividad económica.

- El suelo industrial es el asentamiento de la actividad fabril, (en 2010 según el INE en el País Vasco la industria, sin construcción, aportó el 20,8\% del PIB y 22,4\% de la población ocupada en ese mismo año) que está en estrecha relación con los servicios, llegando a configurarse en los países de alto nivel de desarrollo lo que los expertos han denominado como economía servindustrial. La industria es la principal demandante de un conjunto de servicios muy vinculados a su actividad (ingeniería, logística, servicios tecnológicos ...) y generadora de innovaciones. Por lo que la coexistencia entre usos terciarios e industriales en los parques empresariales es muy recomendable para facilitar las relaciones entre suministradores y clientes que precisan proximidad.

- El suelo industrial exige accesibilidad a las principales infraestructuras de transporte (autopistas, aeropuertos, puertos, áreas logísticas), a grandes áreas de mercado (zonas urbanas) y al mercado laboral. Una localización apropiada para una empresa va a facilitar las relaciones con sus proveedores, con su clientela y va a influir positivamente en la imagen corporativa de esa firma.

- La industria tiende a la concentración. Las economías derivadas de la proximidad siguen estando operativas. No solamente por la disminución de costes de transporte y de tiempo que aportan, sino por la oportunidad que brindan al intercambio informal de información, de experiencias, de conocimiento y de ambiente socio-laboral.

Habría que considerar estos parámetros básicos en el proceso de decisión de la localización futura de suelo industrial para que las inversiones llevadas a cabo por las distintas administraciones públicas sean lo más efectivas posibles y atiendan a las necesidades de las empresas.

Las actuaciones vinculadas a la provisión de suelo para actividades económicas forman parte de la política de desarrollo regional desde las décadas de 1950 y 1960 en el contexto europeo. En España estuvieron dirigidas a la oferta de suelo en polígono industrial por parte 
del INUR (Instituto Nacional de Urbanización) (1956-1976) y posteriormente el SEPES (Sociedad Estatal de Promoción y Equipamiento de Suelo) fue creado en 1980, teniendo en el País Vasco una promoción muy limitada (Caravaca-Méndez, 1996). En la actualidad en Álava, así como en Vizcaya y Guipúzcoa, los programas de suelo están ligados a la promoción del desarrollo empresarial y la competitividad regional, y en general al estímulo de la innovación en el marco de la política regional de la Unión Europea. En el cuadro 1 aparecen algunas variables significativas sobre el suelo para actividades económicas.

Cuadro 1

ASPECTOS RELACIONADOS CON EL SUELO PARAACTIVIDADES ECONÓMICAS

\begin{tabular}{|c|c|c|c|}
\hline \multirow{2}{*}{ GESTOR } & Público & Privado & $\begin{array}{c}\text { Empresa } \\
\text { de capital } \\
\text { público }\end{array}$ \\
\hline
\end{tabular}

\begin{tabular}{|c|c|c|c|c|c|c|}
\hline $\begin{array}{c}\text { TIPO DE } \\
\text { PRODUCTO/ } \\
\text { OFERTA }\end{array}$ & $\begin{array}{c}\text { Parcela } \\
\text { urbanizada, } \\
\text { lista para } \\
\text { construir } \\
\text { edificio, } \\
\text { nave, etc. }\end{array}$ & $\begin{array}{c}\text { Pabellón } \\
\text { llave en } \\
\text { mano } \\
\text { (comunidad } \\
\text { de } \\
\text { propietarios) }\end{array}$ & $\begin{array}{c}\text { Pabellón } \\
\text { llave en } \\
\text { mano (único } \\
\text { propietario) }\end{array}$ & $\begin{array}{c}\text { Plataforma } \\
\text { logística }\end{array}$ & $\begin{array}{c}\text { Edificios } \\
\text { de oficinas } \\
\text { «high tech» }\end{array}$ & $\begin{array}{c}\text { Proyectos } \\
\text { estratégicos }\end{array}$ \\
\hline
\end{tabular}

\begin{tabular}{|c|c|c|c|}
\hline $\begin{array}{c}\text { FORMA DE } \\
\text { ACCESO }\end{array}$ & Alquiler & Compra & $\begin{array}{c}\text { Alquiler con } \\
\text { opción a } \\
\text { compra }\end{array}$ \\
\hline
\end{tabular}

\begin{tabular}{|c|c|c|c|}
\hline $\begin{array}{c}\text { OBJETIV0 } \\
\text { PRIORITARIO }\end{array}$ & $\begin{array}{c}\text { Instalación } \\
\text { de empresas }\end{array}$ & $\begin{array}{c}\text { Programa de } \\
\text { innovación }\end{array}$ & $\begin{array}{c}\text { Rehabilita- } \\
\text { ción urbanís- } \\
\text { tica }\end{array}$ \\
\hline
\end{tabular}

\begin{tabular}{|c|c|c|c|c|}
\hline $\begin{array}{c}\text { TIPO DE } \\
\text { LOCALIZACIÓN }\end{array}$ & $\begin{array}{c}\text { Central } \\
\text { (casco } \\
\text { urbano) }\end{array}$ & $\begin{array}{l}1^{\text {a }} \text { corona } \\
\text { metropolitana } \\
\text { (área de } \\
\text { influencia de } \\
\text { la ciudad a } 30 \\
\text { minutos en } \\
\text { automóvil) }\end{array}$ & $\begin{array}{l}2^{\text {a }} \text { corona } \\
\text { metropolitana } \\
\text { (de } 30 \text { a } 90 \\
\text { minutos en } \\
\text { automóvil) }\end{array}$ & $\begin{array}{l}\text { Ultraperi- } \\
\text { férica (muy } \\
\text { distante de } \\
\text { ciudades, } \\
\text { más de } 90 \\
\text { minutos en } \\
\text { automóvil) }\end{array}$ \\
\hline
\end{tabular}

\begin{tabular}{|c|c|c|c|c|}
\hline \multirow{2}{*}{ DIMENSIÓN } & $\begin{array}{c}\text { Industria } \\
\text { tradicional: }\end{array}$ & $\begin{array}{c}\text { Plataformas } \\
\text { logísticas: }\end{array}$ & $\begin{array}{c}\text { Industria } \\
\text { escaparate: }\end{array}$ & Mininaves: \\
& $\begin{array}{c}5.000-10.000 \\
\mathrm{~m}^{2}\end{array}$ & $\begin{array}{c}2.500-5.000 \\
\mathrm{~m}^{2}\end{array}$ & $500-800 \mathrm{~m}^{2}$ & \\
\hline
\end{tabular}

Fuente: Méndez, 2007, González 2008 y elaboración propia. 
Una vez repasadas esas cuestiones iniciales exponemos los enfoques teóricos que van difundiéndose en la gestión del suelo para actividades económicas: la innovación, la gobernanza y la sostenibilidad.

\section{Innovación}

Los sistemas territoriales de innovación constituyen el discurso teórico que ha inspirado desde 1980 las políticas de desarrollo regional, siendo una de esas políticas la dirigida a dotar el territorio de las infraestructuras necesarias para el desarrollo de la actividad productiva y formando parte de las mismas el suelo para la localización de las empresas. De una reflexión muy completa sobre las diferentes orientaciones teóricas (Méndez 2010: 75-98) quisiéramos destacar la consideración del territorio (entendiendo éste cómo el entramado económico, social, cultural y físico que singulariza un ámbito geográfico de escala variable que puede ir desde la comarca a la región) como sujeto activo en el proceso de innovación. Desde la geografía económica la investigación de «algunas claves externas a la empresa pero internas los lugares donde tienen lugar los procesos de innovación» (Méndez 2010:79) es un objetivo prioritario de investigación. Ese papel relevante del territorio ya es reconocido por organismos internacionales (OCDE, 2011: 63), que destacan la desigual distribución en el territorio de infraestructuras y organismos que promueven la innovación en las regiones, así como de las empresas con alto contenido tecnológico e innovador y del capital humano cualificado. Dicha idea ya fue planteada y contrastada hace dos décadas (Méndez-Rodríguez, 1991). Sin embargo, si bien está demostrado que una parte de la competitividad de la empresa reside en la región donde desarrolla su actividad, se da la paradoja de la innovación regional, en el sentido de que las regiones que más necesitarían invertir en innovación tienen una capacidad limitada para absorber los fondos públicos destinados a las políticas de innovación (Oughton-Landabaso-Morgan, 2002).

La innovación en la gestión del suelo está plasmándose en actuaciones que suponen la utilización efectiva de las TICs (Tecnologías de Información y Comunicación) e Internet para dar nuevos servicios a las empresas y optimizar la gestión de los organismos públicos responsables de la gestión del suelo. En este ámbito podemos citar los SIG (Sistemas de Información Geográfica). Los SIG son una herramienta muy adecuada para gestionar variables territoriales como el suelo e interrelacionarlas con otros aspectos socioeconómicos como el empleo, la tecnología y el conocimiento. Asimismo, los SIG facilitan el seguimiento y evaluación de las políticas regionales de innovación.

La innovación que aportan los SIG consiste en ofrecer un servicio diferente respecto a lo existente que permite la consulta de la oferta de suelo de modo inmediato en formato de mapa (donde, a qué precio, qué dimensión, quien lo gestiona; diagnóstico del perfil sectorial y empresarial de cada polígono incluyendo la dimensión territorial), de una forma diferente (a través de web) y hacia un ámbito geográfico más lejano (desde la web pueden realizar consultas empresas de otras regiones y países, por lo que la versión en inglés es muy recomendable). La innovación potencial que representan los SIG ha de ir acompañada de una gestión también innovadora, que convendría que se plasmara en, al menos, un geoportal que reúna la oferta en un mapa y que redireccione a los diferentes organismos responsables. 
Por otra parte, los SIG permiten capitalizar el conocimiento sobre cada área empresarial. Disponer de la información relativa al tamaño de empresas, tipo de actividad, nivel de exportación, tareas desarrolladas dentro de las empresas (ingeniería, fabricación, almacenamiento ...), residuos generados, entre otros temas, permite diseñar actuaciones y estrategias a nivel de polígono industrial y parque empresarial para generar sinergias a ese nivel intramunicipal, comarcal y regional y, en definitiva, promover la competitividad de las empresas y del territorio.

Diferentes aplicaciones de SIG que muestran la oferta pública de suelo son los de Madrid, Andalucía, La Rioja, Asturias, Álava etc. A nivel nacional sí que sería deseable una aplicación que ofreciera información homogénea de todo el país, pero de momento la coyuntura de crisis económica no va a permitirlo (AAVV, 2011).

\section{Gobernanza}

La gobernanza es entendida como la capacidad para emprender acciones acordadas entre diferentes instituciones públicas y privadas en un ámbito geográfico definido con el objetivo de promover el desarrollo local. En el País Vasco la gobernanza es bastante compleja debido a que la Ley de Territorios Históricos (Ley 27/1983, de 25 de noviembre, de Relaciones entre las Instituciones Comunes de la Comunidad Autónoma y los Órganos Forales de sus Territorios Históricos) legalizó la coexistencia de competencias de los Ayuntamientos con las de las Diputaciones Forales y las del Gobierno Vasco (Gurrutxaga, 2010). Dicha ley ha llevado a la actual densidad institucional que exige coordinación, participación y evaluación. Como señala dicho autor (Gurrutxaga, 2010:74) «la calidad, la eficacia y la legitimidad de la acción pública se fundamentan en la calidad de la interacción entre diversos niveles de gobierno y entre éstos, la sociedad civil y las organizaciones empresariales».

La gobernanza en la gestión del suelo para actividades económicas por parte de organismos públicos tiene proyección en varios temas. Los acuerdos alcanzados para ejecutar proyectos conjuntos de urbanización y gestión de suelo por parte de administraciones de diferentes niveles (desde la Unión Europea hasta el Ayuntamiento) a través de la conformación de sociedades públicas tiene una larga trayectoria en el País Vasco, por ejemplo Industrialdeak (término en vasco que significa textualmente «zonas ó polígonos industriales») y CEIs (Centro de Empresas e Innovación).

Los «Industrialdeak» conceptualmente son parques empresariales que merecen un comentario más pormenorizado por el modelo de gobernanza que han promovido, el volumen de suelo gestionado y su amplia distribución en el País Vasco. La participación de la financiación en cada Industrialdea, que adquiere la forma de sociedad anónima, es desde las tres instituciones con competencias en suelo y en general del siguiente modo: SPRILUR (Gobierno Vasco, más información en punto II.2.) con el 51\% (la parte mayoritaria) y el resto repartido entre Diputación y Ayuntamiento ó entidad comarcal de modo variable. En los Industrialdeak de Guipúzcoa por parte de Sprilur hay cinco representantes, dos por parte de la Diputación y dos del Ayuntamiento. En Vizcaya suelen ser cuatro representantes de Sprilur, tres de la Diputación y uno del Ayuntamiento. En Álava en «Aiara Haraneko Industrialdea» (que gestiona polígonos en los municipios de Ayala, Llodio y Amurrio) y «Lautadako Industrialdea» (ubicado en Vitoria-Gasteiz) Sprilur participa en cada uno de estos 
industrialdeak con el 51\%. En Gilsa (en Parque Industrial y de Servicios de Júndiz, Vitoria) la participación de Sprilur está limitada al $41,77 \%$ y es el Ayuntamiento de Vitoria-Gasteiz el que tiene la parte mayoritaria $(58,22 \%)$.

De hecho, la colaboración interinstitucional con agentes públicos (Diputaciones, Ayuntamientos, Agencias de Desarrollo Comarcal) y privados es uno de los objetivos de Sprilur (Sprilur, 2009). Dicho objetivo obedece al interés en compartir recursos, planificar la gestión urbanística y favorecer la creación de áreas empresariales a nivel local y comarcal. Este modelo de acuerdo ha tenido una amplia aceptación. De 1982 a 2010 en los Industrialdeak y polígonos Sprilur han sido creadas 2.003 sociedades que han generado 25.854 empleos (Sprilur, 2011). Los Industrialdeak se han constituido en auténticos motores de desarrollo local y modelo de las ventajas socioeconómicas logradas a través de los acuerdos entre las diferentes instituciones. El modelo de gobernanza promovido a través de Industrialdeak es prácticamente único en comparación con otras áreas de actuación pública entre Gobierno Vasco, Diputación y Ayuntamientos.

Los Industrialdeak han definido un modelo de gestión en los parques empresariales impulsados por la iniciativa pública en los que las señas de identidad son: calidad del entorno urbanizado y de los pabellones construidos, impulso al tema de la sostenibilidad (estudios de impacto ambiental, gestión sostenible de los parques empresariales: hacia los parques empresariales de cero carbono), creación de empleo y sofisticación en los servicios ofrecidos. El ámbito de Sprilur en suelo comprende además de los Industrialdeak, los «Polígonos propios» (promoción y gestión directa de áreas empresariales) y «Proyectos estratégicos». Sprilur ha abordado la reorganización geográfica de la gestión (tres direcciones provinciales y ocho comarcales) de sus parques empresariales y parques tecnológicos, con el objetivo de ahorrar costes y optimizar la transferencia del conocimiento generado en los diferentes espacios productivos (Iturrate, 2011).

La proyección de Sprilur ha llegado al ámbito internacional y está liderando el proyecto de la Unión Europea MITKE (2008-2011) (Programa Interreg IVC). MITKE, Managing the Industrial Territories in the Knowledge Era, en el que participan regiones de diferentes países de la Unión Europea, tiene por objetivo la identificación y transferencia de las «mejores prácticas» de gestión. El intercambio de experiencias y enfoques ha de promover el mejor funcionamiento de las áreas empresariales en aspectos rutinarios (infraestructura, entorno, gestión, renovación de polígonos) y el impulso hacia la innovación y la sostenibilidad desde el equipo gestor de cada área empresarial, para poder así responder de un modo activo al reto de la economía globalizada.

De momento, los avances señalados por Mora (2006) apuntan hacia la necesidad de establecer fórmulas de gestión que aseguren el mantenimiento adecuado de las áreas empresariales con el objetivo de que faciliten la actividad empresarial, permitan una calidad de vida adecuada a sus trabajadores y prevengan de la formación de áreas degradadas. Una fórmula posible para evitar el deterioro de los parques empresariales es la creación de «Entidades de Conservación». Las Entidades de Conservación son entes que integran obligatoriamente a los propietarios del área bajo la supervisión de un ayuntamiento con el fin de sufragar los gastos de conservación y prestación de servicios públicos obligatorios (abastecimiento de agua, alumbrado, limpieza y mantenimiento de zonas verdes). La contrapartida de estas 
entidades es que los propietarios tienen que asumir los costes de mantenimiento cuando la obligación es de los ayuntamientos. Otra opción es la creación de «Entidades de Gestión Voluntaria», a las que se adhieren las empresas de una zona industrial y mediante convenio con el ayuntamiento correspondiente acuerdan el reparto de responsabilidades y cargas para mantener el parque empresarial en unos estándares de calidad aceptables. Por tanto, asegurar la conservación de los parques empresariales emerge como una prioridad, ya que la calidad del entorno empresarial es un factor relevante en la competitividad regional (Orquestra, 2011: 288)

En este sentido habría que mencionar que la apuesta de la CEPE (Coordinadora Española de Polígonos Empresariales) por sistematizar y homologar procedimientos de gestión en colaboración con AENOR (Asociación Española de Normalización y Certificación) supondrá una aportación significativa a la gobernanza de los parques empresariales.

\section{Sostenibilidad}

El desarrollo sostenible entendido como un desarrollo territorial equilibrado entre el ámbito económico, medioambiental y social va difundiéndose a diferentes ámbitos de actuación pública y ha llegado a la gestión del suelo para actividades económicas.

La aplicación del concepto de sostenibilidad en la gestión del suelo está vinculada a la planificación urbanística y territorial. Mantener un cierto equilibrio a nivel comarcal y local entre el suelo residencial y suelo para actividades económicas sería conveniente para evitar desplazamientos pendulares masivos, que traen consigo contaminación, congestión de tráfico y un deterioro de la calidad de vida.

Por otra parte, habría que evitar el consumo de suelo rural para la urbanización en la medida que sea posible para preservar el paisaje del entorno. El valor del paisaje fue refrendado en el Convenio Europeo del Paisaje (2000) como un activo imprescindible a conservar. El paisaje cultural y natural configura la idiosincrasia de los lugares. Además, plantea la necesidad de integrar el paisaje en las políticas de ordenación territorial y urbanística y en sus políticas en materia cultural, medioambiental, agrícola, social y económica, así como en cualesquiera otras políticas que puedan tener un impacto directo o indirecto sobre el paisaje (BOE, $\left.n^{\circ} 31,1899,5 / 2 / 2008\right)$ y, además, tiene la capacidad de aunar la identidad colectiva de quienes viven en el territorio.

Ya han puesto en marcha mecanismos para cuantificar ese consumo de suelo en áreas urbanas en España, apoyándose en información facilitada por la Oficina del Catastro y gestionada mediante SIG (Jiménez, 2008). Los primeros resultados fueron planteados para «intentar establecer qué tipo de relaciones existen entre las dinámicas espaciales experimentadas por nuestro territorio y aquellas decisiones y procesos socioeconómicos que las han generado, señalando las implicaciones, en términos de sostenibilidad, de los distintos patrones de ocupación» (OSE, 2006). En lo que se refiere al País Vasco uno de los cambios de usos del suelo de 1987 a 2000 más destacado ha sido el aumento de superficies artificiales, tanto en datos absolutos como relativos (3.283 Ha., casi un 14\% de incremento). El aumento de zonas industriales, comerciales y de transportes es el principal factor de demanda $(2.510,6$ hectáreas en ese período), seguido de zonas urbanas (749,8 hectáreas) (OSE, 2006: 402). La ralentización de ese alto consumo de suelo vendrá apoyado por la aprobación del Ante- 
proyecto de Ley del Paisaje del País Vasco (BOPV, 19/4/2011), que señala la necesidad de conservar los paisajes rurales y emprender mejoras paisajísticas en la periferia de los núcleos urbanos, precisamente donde están localizados en buena parte los polígonos industriales y parques empresariales. El Catálogo de Paisaje será el instrumento para la introducción de objetivos paisajísticos en la planificación territorial y proporcionar un contexto a los proyectos particulares (Nogué-Galán, 2011). Por lo que la apertura de líneas de investigación sobre el paisaje configurado por parques empresariales y polígonos industriales resulta oportuno (Caravaca, 2011).

Una forma de minimizar ese consumo de suelo es la reutilización de suelo ya urbanizado y que carece de funcionalidad como las ruinas industriales. Sprilur (2009: 27) recomienda como primera medida para proyectar edificios y áreas industriales sostenibles «utilizar zonas degradadas sobre la urbanización de suelos naturales (...). Se trata de potenciar el uso del suelo que ya había sufrido una alteración de origen antropogénico y preservar así el recurso natural que representa el suelo». También señala que tengan en cuenta la disponibilidad de transportes públicos y la comunicación a los núcleos urbanos al seleccionar la ubicación. Además ofrece una metodología para cuantificar la sostenibilidad mediante una amplia batería de indicadores. Asímismo Sprilur (2010) exige el máximo nivel de desarrollo sostenible en todas las fases de la urbanización (diseño, ejecución, vida útil y demolición).

En relación al «reciclaje» del suelo ya urbanizado para actividades económicas que ha quedado deteriorado habría que señalar los baldíos industriales, ferroviarios y portuarios que han sido recuperados como ejes de la revitalización urbana en numerosas ciudades de antigua industrialización (Bilbao, Londres, Burdeos, Pittsburgh). La reconversión de usos del suelo para usos residenciales, áreas de negocios, culturales y nuevos equipamientos ha significado la revitalización económica de esas zonas y la apuesta por la sostenibilidad urbana de esos distritos renovados (Esteban, 1999). Efectivamente, reciclaje y rehabilitación son conceptos que han de estar presentes en la gestión de la ciudad contemporánea (Ezquiaga-Nel-lo, 2010).

En un nivel más concreto ha ido calando la necesidad de gestionar los polígonos de un modo sostenible y de diseñar herramientas de gestión medioambiental que permitan abordar la escala multiempresarial de un polígono industrial (Fundación Entorno, 2005). La gestión (recogida, reciclaje, eliminación) conjunta de los residuos de las empresas en un polígono, el transporte colectivo y de vehículo privado compartido son algunos de los servicios que han puesto en práctica con el consiguiente ahorro de costes y mejora para el medio ambiente en algunos parques empresariales.

Finalmente, habría que apuntar que en relación a los cambios que van derivándose de la sociedad del conocimiento la demanda de superficie por parte de las empresas será probablemente menor. Esto se debe a que las tareas de fabricación, intensivas en superficie y mano de obra, están siendo relocalizadas en países del este europeo y asiáticos. El tipo de actividades que están prevaleciendo en nuestro entorno son las tareas más intensivas en conocimiento (diseño, innovación, tecnología, marketing ...), que requieren unas dotaciones de suelo de menor dimensión, si bien de alta calidad y equipamiento y en condiciones óptimas de accesibilidad. El proceso de internacionalización del tejido empresarial vasco está generando demandas de suelo en el extranjero y en este contexto habría que situar los acuerdos de colaboración del Gobierno Vasco con la Corporación Mondragón para la creación de Parques Empresariales en países referenciales (China, India, Rusia). 
A esto habría que añadir que a consecuencia de la crisis económica actual están quedando pabellones y naves disponibles que han aumentado la oferta de suelo desde la esfera privada. Este fenómeno de intensificación tecnológica, descentralización productiva y redefinición de los parques empresariales y polígonos industriales ya ocurrió en la crisis económica de los setenta (Comunidad de Madrid-TAP, 1991), siendo las áreas más accesibles al núcleo urbano las que registraron un cambio más intenso. Este conjunto de procesos dio lugar a la terciarización progresiva de áreas industriales tradicionales de los principales núcleos fabriles en el área metropolitana de Madrid, Barcelona y Bilbao (Méndez-Pascual, 2006), (Sánchez, 2009).

En definitiva, el objetivo a promover sería equilibrar el desarrollo socioeconómico y la utilización razonable del suelo en entornos urbanos. En la fase de planificación convendría asegurar la gestión de suelo sostenible. La utilización conjunta de herramientas SIG y SDSS (Spatial Decision Support Systems) facilita la planificación sostenible del suelo industrial (Lamelas, 2009).

La asimilación de la innovación, la gobernanza y la sostenibilidad será más receptiva en los territorios inteligentes, donde esos conceptos han sido absorbidos a nivel social e institucional (Esteban y otros edit. 2008).

\section{LA POLÍTICA DE SUELO INDUSTRIAL EN ÁLAVA}

La política de suelo industrial en Álava está promovida por organismos de diferentes niveles administrativos, desde el ámbito regional al municipal (ver Cuadro 2):

- Diputación Foral de Álava, a través de Álava Agencia de Desarrollo (AAD).

- Gobierno Vasco, por medio de Sprilur y Parque Tecnológico de Álava (PTA).

- Ayuntamiento de Vitoria-Gasteiz, a través de Gilsa.

- Acuerdo institucional local-regional: CEIA.

En Álava los operadores públicos de suelo desempeñan un papel predominante al gestionar el $56 \%$ de la superficie industrial total, frente a la iniciativa privada (44\%). Dada la entidad de sus actuaciones en términos porcentuales y absolutos tienen capacidad para influir de modo evidente en el mercado del suelo para actividades económicas.

Los objetivos que pretenden alcanzar están englobados en la promoción económica del territorio y son:

- Apoyo a la empresa mediante la provisión de infraestructuras necesarias para el desarrollo de la actividad económica en el contexto de la política regional y/o local de innovación.

- Apoyo al empleo, facilitar que las iniciativas empresariales innovadoras vinculadas al autoempleo encuentren un local adaptado a su limitado tamaño y recursos iniciales.

- Equilibrio territorial, distribución de la población y de la actividad económica en las diferentes comarcas de la región y/o territorio histórico.

A continuación veremos las actuaciones de las distintas entidades. 
Cuadro 2

ENTIDADES GESTORAS DE SUELO PARA ACTIVIDAD ECONÓMICA EN ÁLAVA EN 2009

\begin{tabular}{|l|c|c|c|c|c|}
\cline { 2 - 6 } \multicolumn{1}{c|}{} & \multicolumn{5}{c|}{ GESTOR PÚBLICO } \\
\cline { 2 - 6 } \multicolumn{1}{c|}{} & AAD & SPRILUR & GILSA & P.T.A. & C.E.I.A \\
\hline $\begin{array}{l}\text { TIPO DE SUELO/ } \\
\text { PARQUE } \\
\text { EMPRESARIAL } \\
\text { GESTIONADO }\end{array}$ & $\begin{array}{c}\text { Parcelas } \\
\text { urbanizadas } \\
\text { Pabellones en } \\
\text { alquiler }\end{array}$ & $\begin{array}{c}\text { Industrialdeak } \\
\text { Polígonos } \\
\text { propios } \\
\text { Proyectos } \\
\text { estratégicos }\end{array}$ & $\begin{array}{c}\text { Parcelas } \\
\text { urbanizadas }\end{array}$ & $\begin{array}{c}\text { Parcelas } \\
\text { urbanizadas } \\
\text { Pabellones en } \\
\text { alquiler }\end{array}$ & $\begin{array}{c}\text { Pabellones en } \\
\text { alquiler }\end{array}$ \\
\hline $\begin{array}{l}\text { ÁMBITO } \\
\text { GEÓGRAFICO } \\
\text { DE ACTUACIÓN }\end{array}$ & $\begin{array}{c}\text { Álava, excepto } \\
\text { municipio de } \\
\text { Vitoria-Gasteiz }\end{array}$ & País Vasco & $\begin{array}{c}\text { Municipio de } \\
\text { Vitoria-Gasteiz }\end{array}$ & $\begin{array}{c}\text { Pueblo y concejo } \\
\text { de Miñano } \\
\text { (Vitoria-Gasteiz) }\end{array}$ & $\begin{array}{c}\text { Edificio CEIA } \\
\text { en PTA }\end{array}$ \\
\hline $\begin{array}{l}\text { SUPERFICIE } \\
\text { TOTAL }{ }^{2}\end{array}$ & \begin{tabular}{c} 
6.286.568 \\
\hline
\end{tabular} & 486.045 & 5.919 .832 & 1.178 .454 & 2.700 \\
\hline
\end{tabular}

Fuente: Alavamap y elaboración propia.

SUPERFICIE DE SUELO POR ENTIDAD GESTORA EN 2009

\begin{tabular}{|c|c|c|c|}
\cline { 2 - 4 } \multicolumn{2}{c|}{} & SUPERFICIE $\left(\mathbf{m}^{2}\right)$ & Porcentaje (\%) \\
\hline \multicolumn{2}{|c|}{ Álava Agencia de Desarrollo } & 6.286 .568 & 24,72 \\
\hline \multirow{2}{*}{ Ayuntamiento de Alegría-Dulantzi } & 402.712 & 1,58 \\
\hline \multirow{3}{*}{ Sprilur } & Lautadako Industrialdeak & 27.835 & 0,11 \\
\cline { 2 - 4 } & Aiara Haraneko Industrialdeak & 30.739 & 0,12 \\
\cline { 2 - 4 } & Sprilur & 427.471 & 1,68 \\
\hline \multicolumn{2}{|c|}{ Parque Tecnológico de Álava } & 1.178 .454 & 4,63 \\
\hline \multicolumn{2}{|c|}{ Gilsa (Jundiz) } & 5.919 .832 & 23,28 \\
\hline \multicolumn{2}{|c|}{ Otros (Inmobiliarias, particulares, etc.) } & 11.152 .506 & 43,86 \\
\hline \multicolumn{2}{|c|}{ TOTAL } & 25.426 .117 & 100 \\
\hline
\end{tabular}

Fuente: Alavamap y elaboración propia.

\section{1. Álava Agencia de Desarrollo (AAD)}

La Diputación Foral de Álava (DFA), a través de Álava Agencia de Desarrollo viene desarrollando, entre otras tareas, la urbanización, y gestión de suelo industrial desde 1991 Estas labores relativas a la oferta de suelo están inscritas en el contexto de la política de promoción económica de la institución foral. Previamente, la DFA, junto a la Caja de Ahorros Provincial de Álava, se ocupaba de preparar suelo industrial a finales de la década de 1970 de cara a facilitar la descentralización de empresas desde Vitoria a los municipios de Legutiano, Asparrena, Salvatierra, Lantarón y Ayala. 
A partir de 1991 AAD emprende la promoción de diferentes polígonos industriales (ver mapa 1) continuando la política de reequilibrio territorial que pretende una distribución más homogénea de la población y la actividad económica en el territorio alavés. Recordemos que en 1995 el empleo industrial concentrado en Vitoria supone el 61,4\% respecto a Álava, según DIRAE (Directorio de Actividades Económicas) de Eustat (Instituto Vasco de Estadística). Asimismo, el reconocimiento social de la pequeña y mediana empresa (pyme) en la creación de empleo, la escasez de grandes inversiones como en el desarrollismo, la puesta en valor de recursos locales y la mejora de la red de transportes y comunicaciones van a favorecer la asimilación del concepto del desarrollo endógeno por parte de las instituciones (Vazquez Barquero, 2007). Un pilar imprescindible en el apoyo al desarrollo local es la dotación de suelo para facilitar la ubicación de las empresas. El diferente comportamiento de las regiones ante la creación de empresas ha motivado diversas investigaciones en torno al concepto de emprendizaje, cuyo indicador estadístico mide la aparición de empresas, entre otros parámetros, en un ámbito espacial. Como señala Basagoiti (2008): «El emprendizaje, como concepto con entidad propia o bien asociado con el de innovación, está de plena actualidad en los ámbitos académicos y políticos de nuestro país».

Entre 1995 y 2005 AAD promueve varios polígonos industriales de nueva planta (en Iruña de Oca, Laguardia, Lanciego, Lapuebla de Labarca y Okondo) y la ampliación de otros ya existentes (Asparrena, Ayala, Lantarón, Legutiano, Llodio y Salvatierra).

AAD (al 1/1/2010) gestiona una superficie total de suelo para actividades económicas de 6.286.568 metros cuadrados, que suponen un $25 \%$ de la superficie industrial total en Álava y un $44 \%$ de la superficie gestionada por operadores públicos en esta provincia.

El nivel de ocupación (superficie de parcelas AAD*100/ superficie total de parcelas ocupadas AAD) en los polígonos de AAD es del 92,3\%. Un grado de ocupación bastante alto que confirma la oportunidad de las actuaciones llevadas a cabo en años anteriores como soporte activo para el desarrollo local. En un nivel de ocupación muy similar el resto de polígonos de Álava $(88,7 \%)$.

La oferta de suelo disponible por parte de AAD (según la información aportada por web de AAD al 1/1/2010) sería la siguiente:

- Salvatierra. En el P.I. Galzar $\left(97.307 \mathrm{~m}^{2}\right)$ y en el P.I. Agurain $\left(17.541 \mathrm{~m}^{2}\right)$ quedan parcelas urbanizadas para la venta.

- Iruña de Oca. En el P.I. Subillabide $\left(139.561 \mathrm{~m}^{2}\right)$ quedan varias parcelas libres al haber finalizado la ampliación de P.I. San José de los Llanos recientemente.

- Asparrena. En el P.I. Asparrena-San Millán (15.000 m²) están preparadas un par de parcelas para su adquisición.

En resumen, la superficie total disponible está localizada en Asparrena-San Millán $15.000 \mathrm{~m}^{2}$, Salvatierra $114.848 \mathrm{~m}^{2}$ e Iruña de Oca $139.561 \mathrm{~m}^{2}$, que vendría a satisfacer la demanda potencial en el corredor industrial de la A-1. No hay suelo disponible en ninguno de los polígonos de los municipios de Legutiano, Lanciego, Lantarón, Lapuebla de Labarca. La oferta de 26 pabellones en alquiler en Iruña de Oca (P.I. Subillabide) para empresas de nueva creación y unidades de I+D de las empresas amplía la gama de recintos para albergar empresas. Estos pabellones en alquiler actuarían de incubadora de nuevas iniciativas y significa el enlace entre la política del suelo y fomento del emprendizaje. La política de AAD ha estado basada en una oferta de suelo a un precio asequible, que ha conseguido hacer 
despegar la industria en el eje de la A-1 Madrid-Irún (Iruña de Oca, Salvatierra, Asparrena) y en el sur de Álava (paralelo al eje de la A-68, desde Lantarón a Lanciego). Esta dotación de suelo para actividades económicas ha tenido una gran aceptación, ya que apenas queda suelo disponible, y ha conseguido compensar en parte las disparidades en la distribución de la población y las empresas en el territorio. Sin embargo, de cara al futuro convendría que AAD diversificara el tipo de oferta. Esta transición en el servicio prestado vendría de ampliar la oferta del polígono industrial al parque empresarial tal y como ha empezado con la oferta de pabellones llave en mano en Iruña de Oca.

El cambio sectorial y empresarial en la etapa actual viene representado por la economía servindustrial, caracterizada por una intensa interrelación entre empresas industriales y de servicios y de éstas entre sí (Méndez, coord. 2008: 29). Esta modificación en el marco de transacciones intersectoriales e intrasectoriales demanda parques empresariales con un alto nivel de equipamiento, donde la mezcla de usos y tipo de edificaciones parece oportuno dada la compatibilidad entre la industria ligera y los servicios, así como los habituales flujos entre empresas manufactureras y terciarias. La disposición de pabellones donde la planta baja está dedicada al taller y la segunda planta es la oficina es un modelo de gran aceptación. Asimismo, la ubicación de edificios para oficinas en el mismo recinto del parque con servicios comunes (seguridad, recepción, cafetería, etc.) parece muy recomendable. Las peculiaridades socioeconómicas de cada municipio darán la clave en el diseño de los recintos empresariales en cada localización.

Esta diversificación de la oferta del suelo para actividades económicas por parte de AAD ha de ser una apuesta por la calidad y menos intensiva en el consumo de suelo. Efectivamente, Álava es el territorio histórico que dispone de más suelo en el País Vasco. Frente a la acuciante escasez de suelo en Vizcaya y Guipúzcoa, Álava debido a un proceso de industrialización más tardío y ordenado urbanísticamente, así como a una orografía menos accidentada, dispone de suelo para actividades económicas. La urbanización de dicho suelo puede ejecutarse además a un menor coste por la disposición de zonas llanas. De hecho, la ventaja comparativa con la que cuenta Álava en el suelo le permite asimilar nuevos establecimientos de empresas vizcaínas y guipuzcoanas (por ejemplo, la empresa guipuzcoana Fundiciones WEC, de Deba, que ha abierto un segundo establecimiento en Salvatierra), además de albergar las iniciativas locales y de capital exógeno.

Orientar parte de la oferta del suelo para actividades económicas por la calidad (pabellones llave en mano para empresas de servicios e industriales) en determinadas ubicaciones es una apuesta más firme a medio y largo plazo en el contexto de los territorios inteligentes. La competencia por el precio y la cantidad es poco estable, ya que puede surgir otro operador de suelo que lo oferte en mejores condiciones. La opción por la calidad a un precio competitivo se adapta mejor a las condiciones de los factores productivos de una región con alto nivel de vida como el País Vasco y un proceso de globalización imparable.

Un estudio sobre el suelo industrial en el área metropolitana de Zaragoza (Escalona, y otros, 2007) revela que la dotación de un polígono industrial es un factor valorado por las empresas con el siguiente perfil: de tamaño medio, propietarias del inmueble, sede central, instalación reciente, relocalizadas desde zonas más céntricas del área metropolitana y de intensidad tecnológica media. 
Por otra parte, conviene señalar que en Álava el suelo calificado para actividades económicas es suelo previamente integrado en el medio rural y que supone un deterioro ambiental en el paisaje dicho cambio de utilización. Compatibilizar la disponibilidad de suelo para la creación de empresas y minimizar el impacto en el entorno es un aspecto crucial en el avance de la sostenibilidad. En este sentido asegurar que el suelo calificado y urbanizado para actividades está siendo y será utilizado es una cuestión de responsabilidad social y territorial.

La diversificación de la oferta del suelo para actividades económicas por parte de AAD ya tiene el precedente del polígono Goiain en Legutiano, donde existe una zona de oficinas y otra de empresas industriales. Esta combinación de usos parece ser uno de los factores que explican la consolidación de dicho polígono por las interrelaciones establecidas entre algunas empresas. Méndez (2006: 63) señala que «la diversificación es ahora una de las tendencias más acusadas, con el objetivo de generar entornos capaces de acoger, tanto a microempresas en fase de consolidación, como a establecimientos de pequeñas dimensiones donde las empresas realizan tareas diversas - a menudo no fabriles-, sin renunciar a la posible instalación de grandes factorías o de empresas auxiliares dedicadas al transporte o la logística». En el congreso sobre suelo para actividades económicas e innovación (Proinland) organizado por Sprilur (2008) diferentes ponentes de Reino Unido, Francia y España (G. Hall, I. Gitton, I. Caravaca) llegaban a una conclusión similar.

La ubicación futura de parques empresariales mixtos debería tener en cuenta características socioeconómicas y productivas del municipio, la accesibilidad y la demanda potencial. Una propuesta sería la localización en Murguía y en Salvatierra. Murguía es una localidad del municipio de Zuia especializada en residencia de alta calidad, junto a la autovía que une Vitoria con la autopista a Bilbao, Logroño y Zaragoza, y que disfruta de un entorno ambiental privilegiado, próximo al Parque Tecnológico de Álava y al aeropuerto. Este enclave, a 20 $\mathrm{km}$ de la capital vitoriana y quince minutos en automóvil, con una imagen territorial impecable podría albergar un complejo de oficinas y pabellones. Esta dotación de suelo empresarial equilibraría parcialmente la superficie residencial $(243,76 \mathrm{Ha}$.) y la dedicada a actividades económicas (14,24 Ha.) (Udalplan), posibilitando la atenuación de los movimientos pendulares residencia-trabajo. Otra posibilidad sería en la vecina localidad de Etxabarri-Ibiña (Zigoitia), donde está localizado el centro comercial Gorbeia, junto a la autovía de Altube (N-622) a 10 minutos en vehículo privado de Vitoria.

Por otra parte, Salvatierra emerge como centro industrial y logístico en el eje de la A-1 entre Vitoria (a 30’), Pamplona (47’) e Irún (75’). Su estratégica localización, próxima a la bifurcación hacia Francia y al valle del Ebro, junto a clientes y proveedores de las zonas industriales alavesas, navarras y guipuzcoanas, ha sido capitalizada por empresas del metal y de logística. La concentración de empresas (que reúnen a 1.019 empleados en 2009) y probable crecimiento, superada la crisis, hacen prever una demanda de pabellones de oficinas. En Salvatierra, junto al polígono de AAD, Sprilur también ha urbanizado una parte denominada Polígono Saui-2. Si bien cada organismo tiene su ámbito geográfico de actuación, en algunos casos coinciden en los municipios y la colaboración entre instituciones ha dado lugar a áreas empresariales contiguas espacialmente. Este acuerdo evita la dispersión de zonas industriales en un mismo municipio, lo cual puede minimizar las consecuencias negativas en el medioambiente y en la ordenación urbanística del propio núcleo urbano. Además, favorece la concentración de las empresas, tendencia innata en lo que se refiere a su localización, y 
puede optimizar el uso de áreas e infraestructuras comunes (restauración, depuradora, parking, seguridad ...).

\section{Sprilur y el parque tecnológico de Álava (PTA)}

El Gobierno Vasco ejecuta la política de suelo para actividades económicas en Álava (al igual que en Vizcaya y Guipúzcoa) a través del ente Sprilur. El Parque Tecnológico de Álava (PTA) está más vinculado a la política de innovación del gobierno regional, aunque su repercusión territorial es muy relevante.

Sprilur fue creada en 1995 como Sociedad pública adscrita al Departamento de Industria, Comercio y Turismo del Gobierno Vasco. Su función es planificar, coordinar y diseñar todas las estrategias de reordenación efectiva de la oferta pública de suelo, pabellones industriales y oficinas de la Comunidad Autónoma del País Vasco para continuar y ampliar la tarea que previamente realizaba la SPRI desde 1982, gestionando el programa Industrialdeak (polígonos industriales). Sprilur surge como instrumento de promoción industrial y empresarial, para fomentar e impulsar a través del desarrollo de infraestructuras inmobiliarias industriales la expansión de la actividad económica en Álava, Guipúzcoa y Vizcaya. Su cometido es asegurar la existencia de suelo en cantidad y calidad suficientes a precios competitivos para favorecer la implantación y expansión de todo tipo de actividad económica.

En la evolución en la política del suelo de SPRI y posteriormente de Sprilur pueden distinguirse dos fases (Torres, 1995; Pérez de la Peña, 2008):

$1^{\text {a }}$ Fase de 1982 a 1994, realizan el lanzamiento y consolidación del programa «Industrialdeak».

$2^{\text {a }}$ Fase de 1995 a la actualidad, el crecimiento y diversificación de las actuaciones presiden los ejes de gestión y pueden resumirse en lo siguiente:

- Ubicación de nuevos parques empresariales «Industrialdeak» (participación societaria y gestión indirecta).

- Creación de los «Polígonos propios» (promoción y gestión directa).

- Avanzar en temas de gestión de los parques empresariales (organización de congresos, MITKE, sostenibilidad etc.).

- Necesidad de rehabilitar los industrialdeak construidos y urbanizados hace casi tres décadas.

La provisión de suelo de Sprilur en Álava está concentrada en los municipios de mayor tradición industrial (Vitoria, Llodio, Amurrio y Salvatierra), en localidades de dinamismo empresarial reciente (Lantarón e Iruña de Oca) y una zona de la montaña alavesa (Campezo).

Sprilur es, junto con AAD, uno de los dos principales operadores de suelo. En Álava de 1982 a 2008 en los parques empresariales (industrialdeak y polígonos propios) de Sprilur fueron creados 1.074 empleos, lo que supone un $6 \%$ respecto al total de los empleos creados en el País Vasco en los parques de este organismo (www.sprilur.es). En el período 2008-2012 Sprilur tiene previsto ejecutar en Álava varias actuaciones en localizaciones donde existe una demanda detectada (Legutiano, Vitoria y Amurrio), coincidiendo con áreas tradicionales del desarrollo económico. Esta decisión locacional en materia de oferta de suelo para actividades económicas representa una apuesta por ofrecer a las empresas una opción realista para ubicar sus negocios y para contener la especulación del suelo para actividades económicas en las 
áreas urbanas más densas. En el municipio Valle de Arana ya está concluida la edificación de un parque empresarial para promover la creación de empleo de un área desfavorecida de la montaña alavesa. Las actuaciones de Sprilur en Álava han tenido probablemente menor eco que en Guipúzcoa y Vizcaya desde el punto de vista de la renovación del paisaje industrial y la oferta de parques empresariales de calidad. En Álava el punto de partida era un urbanismo industrial paradigmático y existía la «materia prima» del suelo en abundancia.

Por otra parte, está prevista la construcción de un parque empresarial próximo al aeropuerto alavés de Foronda. La DFA ha cedido a Sprilur más de 600.000 metros cuadrados para impulsar el proyecto Vitoria Industrial Air Park (VIAP), planteado en 2001 y retomado a principios de 2010. La localización de dichos suelos estratégicos y en reserva puede apreciarse en el mapa específico del «Plan Director de la estrategia de la ciudad Vitoria-Gasteiz 2015», accesible en Internet.

Sprilur, como decíamos en el apartado I.2. y I.3, ha sido ejemplo de gobernanza y desde 2008 ha abogado por la sostenibilidad de modo firme. El resultado ha sido el siguiente documento de metodología «Guía para el desarrollo sostenible de sus proyectos de urbanización» (2010). El objetivo de esta guía es definir criterios, medidas y acciones a introducir en las urbanizaciones, que garanticen el máximo nivel de desarrollo sostenible en las fases de diseño y redacción del proyecto, ejecución de las obras, la vida útil de esa urbanización, su mantenimiento y su futura posible demolición.

Por otra parte, una oferta de suelo planteada como instrumento para fomentar la innovación es la gestionada por el Parque Tecnológico de Álava (PTA) ubicado en Miñano (VitoriaGasteiz). Las empresas seleccionadas para poder ubicarse han de caracterizarse por un alto contenido tecnológico e innovador y pueden instalarse en edificios totalmente equipados en régimen de alquiler ó mediante la adquisición de parcelas. Con 3.400 empleos, en 115 empresas y una facturación de 769 millones de $€$ (al 31/12/2009) puede afirmarse que está totalmente consolidado el parque tecnológico alavés. Es más, está prevista una ampliación en los próximos tres años de 900.000 metros cuadrados. El grado de ocupación es del $62 \%$. De cara a integrar los principios de sostenibilidad en el sentido de evitar el consumo de suelo rural tal vez deberían replantearse la densidad de edificación, muy baja actualmente.

Este Parque reúne en Álava la mayor concentración de empresas a la vanguardia tecnológica e innovadora, unidades de $\mathrm{I}+\mathrm{D}$, centros tecnológicos y personal de alta cualificación, constituyendo un entorno privilegiado para el intercambio del conocimiento. Es uno de los principales pilares del sistema regional ciencia-tecnología-empresa en Álava para promover las interacciones en un espacio geográfico concreto y un sólido cimiento, junto a los parques tecnológicos en Zamudio (Vizcaya) y Miramón (San Sebastián) para la conformación del territorio inteligente en el País Vasco.

\section{GILSA (Gasteizko Industria Lurra, S.A.)}

Gilsa es la entidad encargada de gestionar el Polígono Industrial y de Servicios de Júndiz en Vitoria-Gasteiz. Júndiz es una de las dos grandes zonas empresariales de la capital vitoriana, junto con Gamarra (para una visión conjunta de la industria en la capital alavesa ver el capítulo «Vitoria-Gasteiz» en Méndez, 2010). Este polígono fue inicialmente promovido por el Ayuntamiento de Vitoria-Gasteiz a principios de la década de 1980 y en 1993 es creada 
Gilsa con la participación de Sprilur. Este polígono disfruta de un emplazamiento inmejorable en el eje de la A-1: a $3 \mathrm{~km}$ de la capital alavesa, $8 \mathrm{~km}$ del aeropuerto, muy próximo a las zonas industriales de Ali-Gobeo y de la multinacional del automóvil Mercedes y a $15 \mathrm{~km}$ del polígono de Subillabide en Iruña de Oca. En Júndiz están localizadas dos infraestructuras vinculadas a la actividad industrial: el Centro de Transportes de Vitoria y la estación de mercancías de RENFE, configurando un área logística de primera entidad. El Puerto de Bilbao (mediante la participación en Servicios Integrales Vitoria Depot) ha instalado un «puerto seco» de 25.000 metros cuadrados en Júndiz en 2007 y que apunta a convertirse en el área logística de mayor envergadura en el País Vasco y área de influencia (Navarra, Burgos, La Rioja). En el Polígono de Júndiz también está ubicado el Centro Municipal de Empresas de Júndiz, que es la incubadora de empresas del Ayuntamiento de Vitoria-Gasteiz, donde compañías con antigüedad inferior a tres años pueden encontrar un local en condiciones muy atractivas para arrancar su actividad.

La oferta de Gilsa está dirigida a la venta de suelo y disponen de parcelas desde 2.500 metros cuadrados, dimensión que suele ser adquirida por empresas pequeñas (10-15 empleos). El nivel de ocupación (al 31/12/2009) era del 67 \% con las ampliaciones de Júndiz al este (sector 20) y al oeste (sector 21), conformando un parque empresarial de siete millones de metros cuadrados y 13.119 empleos. Gilsa ya dispone de su SIG operativo, servicio calificado muy positivamente por las empresas dada la extensión del mayor parque empresarial de Vitoria. Con objeto de ampliar el tipo de oferta de Gilsa en Júndiz establecieron un Industrialdea (Lautadako Industrialdea), que ofrece pabellones y oficinas llave en mano, dando opciones de establecerse a pequeñas empresas.

La zona de servicios y ocio de Júndiz tiene finalizada una primera fase en la que ya están disponibles oficinas llave en mano, hotel, banco y gimnasio. De este modo va quedando equipado el parque de Júndiz y facilitando la integración entre empresas industriales y de servicios. Sin embargo, el coste paisajístico de la ampliación no puede ignorarse. La última ampliación del Polígono de Júndiz ha rodeado físicamente al pueblo y concejo de Margarita, que forma parte de la zona rural suroeste de Vitoria. El crecimiento urbano de Vitoria, y en particular del suelo para actividades económicas, debería plantearse una moratoria y una serie de actuaciones efectivas a favor de la sostenibilidad.

\section{CEIA (Centro de Empresas e Innovación de Álava)}

CEIA es un organismo creado por la SPRI, el Ayuntamiento de Vitoria-Gasteiz y la Diputación de Álava en 1988 para promover y apoyar la aparición de nuevas empresas. En 1997 son inauguradas sus actuales instalaciones en el Parque Tecnológico de Álava Está integrado en la Red Europea de Centros de Empresa e Innovación. Tiene por objetivo asesorar a emprendedores de perfil innovador para que los proyectos empresariales tengan mayores garantías de éxito. Esta incubadora de empresas dispone de un edificio de 2.700 metros cuadrados, con oficinas donde madurar el proyecto y posteriormente albergar la primera fase de las nuevas firmas. 


\section{ALAVAMAP}

Alavamap es un SIG sobre el suelo industrial en Álava, promovido por Álava Agencia de Desarrollo (AAD). Alavamap nace con el objetivo de facilitar la gestión del suelo en la que trabajan diferentes organismos públicos (AAD, GILSA, SPRILUR), ofrecer un geoportal común al usuario y extraer el conocimiento geoeconómico de la información territorializada. Es un proyecto de gobernanza porque ha consensuado la colaboración de diversos organismos institucionales (DFA, Gobierno Vasco y Ayuntamiento de VitoriaGasteiz), innovación porque da solución al problema de la fragmentación de información de un modo nuevo respecto a lo existente y sostenibilidad porque pone las bases para conocer la oferta pública y privada de suelo sobre las que promover una planificación territorial y urbanística más coherente con el uso responsable del recurso suelo. En base a la información obtenida de Alavamap (al 1/9/2009) hemos alcanzado una serie de resultados que presentamos a continuación.

El proceso de industrialización en Álava fue relativamente tardío (intensificación a partir de 1956), concentrado territorialmente y ordenado urbanísticamente (Álvarez-Torres, 2008). El retraso temporal de la onda industrializadora permitió una planificación urbanística en Vitoria ejemplar en el contexto vasco y español. Las magníficas condiciones de suelo para que se establecieran las empresas, junto a otros factores, impulsaron decididamente la concentración industrial en Vitoria. A finales de la década de 1970 desde la Diputación Foral de Álava consideraron oportuno impulsar una descentralización industrial hacia otros municipios alaveses como Salvatierra y Legutiano, tal y como comentábamos en el apartado 1 de la sección II

La distribución del empleo industrial en Álava nos muestra una estructura monocéntrica y varios ejes articulados en torno a las principales carreteras. El nodo principal es Vitoria, en cuyo entorno inmediato aparecen Legutiano (en la N-240) e Iruña de Oca (en la A-1) y siguiendo el eje de la A-1 hacia Irún destaca Salvatierra. En el eje de la autopista vasco-aragonesa (Bilbao-Zaragoza, AP-68) están Llodio y Amurrio, muy próximos a Bilbao, siguiendo esa misma vía rápida, en el sur de Álava, en la conocida comarca de la Rioja Alavesa, despuntan Laguardia y Oyón.

Estas breves pinceladas nos introducen en el contexto donde son aplicadas las políticas de suelo y, en comparación con Guipúzcoa y Vizcaya, destaca el limitado alcance territorial de la industria en el ámbito alavés, a pesar de su enorme repercusión económica y social. De los 51 municipios que integran Álava los polígonos industriales y/o parques empresariales están ubicados en tan sólo 21 municipios y distribuidos en 46 polígonos industriales y/o parques empresariales (ver mapa 1).

Respecto al volumen de suelo por municipios destacan Vitoria $(54,6 \%)$ (que concentra además el 72,1\% del empleo), Legutiano con el 10,8\% y Salvatierra con el 6,8\% en 2009 (según datos de Alavamap). Los municipios de Ayala, Llodio y Amurrio, próximos a Bilbao, cuya industrialización y morfología está vinculada a la industrialización vizcaína tienen una participación escasa $(0,8 \%, 4 \%$ y 3,5\% respectivamente). En Llodio habría que destacar la carencia de suelo y su particular accidentada orografía, típico de la industrialización en Vizcaya. Por otra parte, existen varios municipios donde su volumen de suelo respecto al total es muy limitado (inferior al 1\%) como en Bernedo, Elburgo, Lapuebla de Labarca, Okondo, 


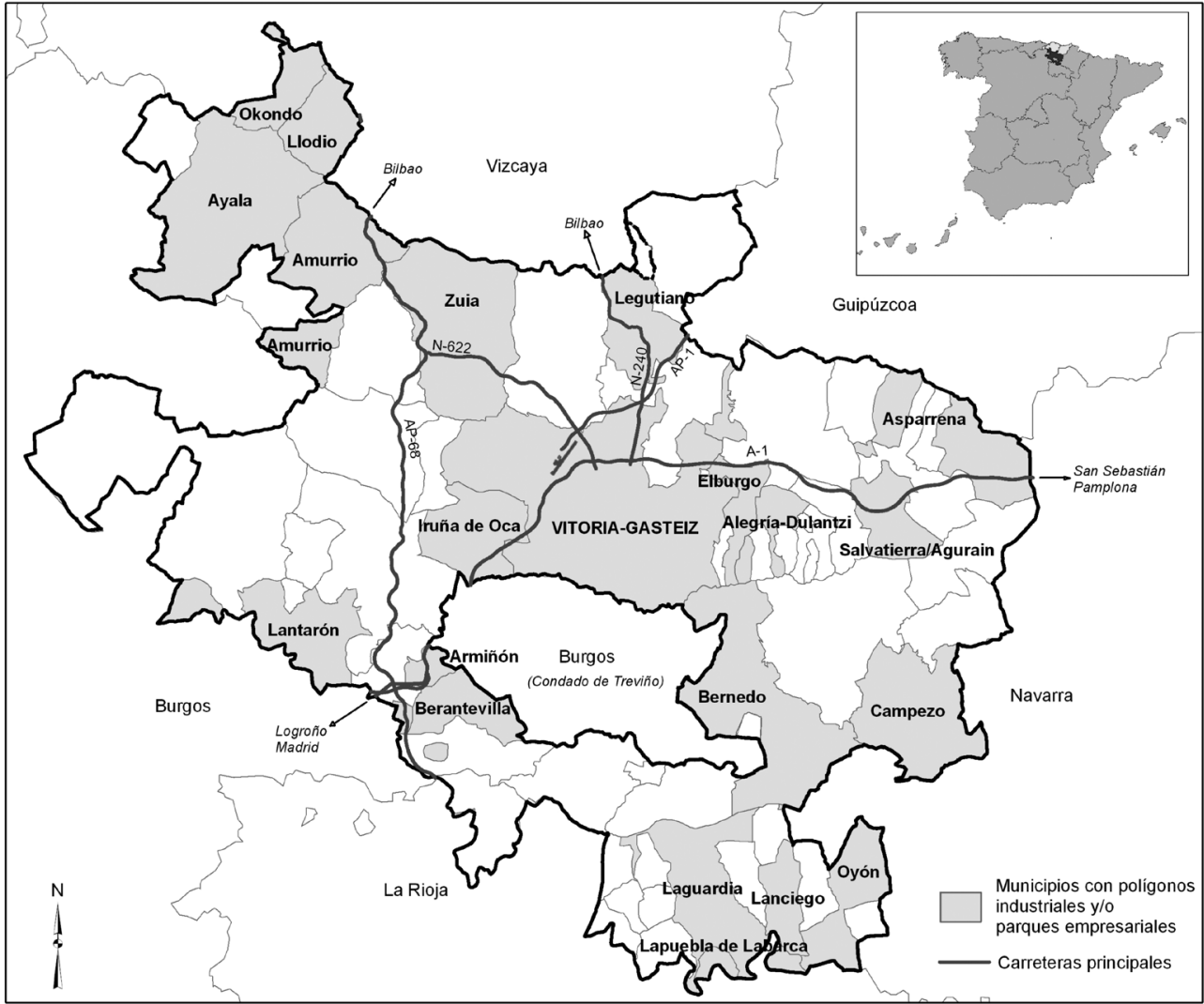

Fuente: Alavamap y elaboración propia.

Armiñón, Ayala, Berantevilla, Campezo y Zuia. En la mayoría de dichos municipios la pauta locacional corresponde a empresas dispersas sin llegar a conformar un polígono industrial.

El grado de ocupación en general es bastante alto, con una media del 86\%. Esto estaría en relación con el cumplimiento de la normativa urbanística, ya que mayoritariamente las empresas industriales han ocupado el suelo calificado para dicha actividad, así como el período de intenso crecimiento industrial en Álava de 1995 a 2007 y a la escasa dispersión de la industria por las amplias zonas rurales de la provincia, donde es casi inexistente. En este sentido habría que subrayar la especial diligencia de la DFA y del Ayuntamiento de VitoriaGasteiz en la vigilancia del cumplimiento de la normativa urbanística.

La desagregación por municipio muestra que los niveles más bajos de ocupación están en relación con una oferta reciente (2000-2010) de suelo (Salvatierra, Iruña de Oca). En el resto de los municipios la ocupación media es superior al 90\%. La distribución de metros cuadrados por trabajador muestra que los niveles de mayor intensidad de uso del suelo (menos $\mathrm{m}^{2}$ por trabajador) se dan en Vitoria, Llodio y Amurrio. Es precisamente en estos tres munici- 


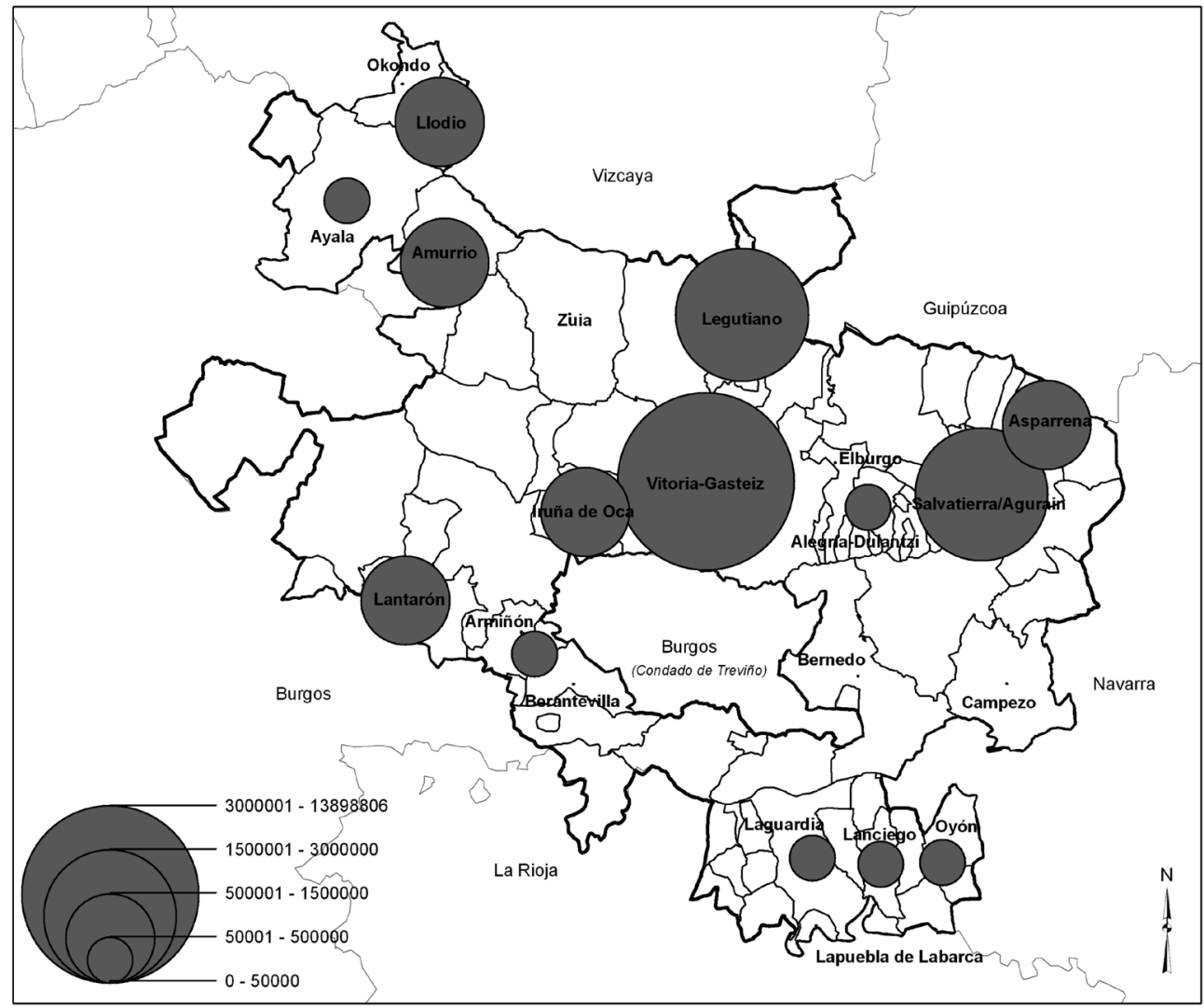

Fuente: Alavamap y elaboración propia.

pios donde se sitúan las empresas más grandes y con el mayor número de trabajadores. Es decir, la mayor intensidad de suelo se sitúa en los lugares de mayor tradición industrial, de mayor centralidad y de coste del suelo más alto. En el resto de los municipios predominan las pequeñas y medianas empresas. En este sentido destacan Salvatierra y Legutiano, que con un $6,8 \%$ y un $10,8 \%$ del suelo industrial de Álava sólo absorben el 1,5\% y el 5,8\% del empleo respectivamente.

En general Alavamap dibuja una imagen de oferta de suelo liderada por operadores públicos en la que sigue predominado la fuerza centrípeta de Vitoria, en torno a la que está consolidada una primera corona industrial integrada por Iruña de Oca, Legutiano y Salvatierra. Si comparamos la evolución territorial de la oferta de suelo industrial con Madrid (Méndez, dir. 2006; Gutiérrez Puebla, 2004), metrópoli en la que la estructura monocéntrica era dominante, vemos que en la metrópoli madrileña han pasado a destacar en la oferta de suelo industrial las coronas más distantes, segunda y tercera. Sin embargo, en Vitoria sigue predo- 
minando la oferta de suelo en el municipio central. Esto es debido a que la capital alavesa sigue reuniendo las economías de aglomeración a diferencia de los municipios de su primera corona donde la oferta de servicios para empresas y la población es muy limitada. La ciudad intermedia de Vitoria ha compartido con otras urbes españolas de ese tamaño un notable dinamismo en el comportamiento del empleo y la población de 2001 a 2006 (Méndez, R. edit. 2010). De hecho, la oferta de suelo en el sur de Álava (Laguardia, Lanciego, Oyón) está vinculada directamente a la proximidad a la ciudad intermedia de Logroño.

\section{CONCLUSIONES}

- El reto de la gobernanza en la planificación y gestión del suelo industrial sigue estando vigente. Si bien las diferentes entidades gestoras de suelo atesoran una valiosa experiencia de trabajo en común tendrían que aunar esfuerzos en validar metodologías de gestión de suelo innovadoras que integren el conocimiento geoeconómico y prácticas sostenibles. AAD y Sprilur ó en otras palabras las instituciones que representan (Diputación Foral de Álava y Gobierno Vasco respectivamente) coinciden en el territorio alavés en el que actúan. A esta duplicación de instituciones en una misma materia y ámbito espacial habría que añadir al Ayuntamiento de Vitoria-Gasteiz en su municipio, en el que coinciden los tres niveles institucionales, por lo que afianzar las posibles sinergias es una obligación inexcusable.

- La innovación que representan los SIG en la gestión del suelo industrial requiere de una actualización periódica de la información que estimule su uso. Por otra parte, los SIG facilitan la gestión coordinada de residuos de las empresas, la toma de decisiones locacionales dentro del parque empresarial (rutas internas de transporte, ubicación de puntos de información, necesidades de mantenimiento y seguridad etc.). A un nivel más general permiten la definición de estrategias territoriales a medio plazo que apuesten por las ventajas comparativas de cada comarca.

- La aplicación de buenas prácticas en la previsión y utilización responsable del recurso suelo en los distintos niveles decisorios (local, regional, nacional) tanto desde el ámbito público como desde el privado habría que situarla en el contexto de la nueva cultura del territorio (Tarroja-Camagni, coord. 2006). Sería muy recomendable que introdujeran mecanismos para abreviar los trámites de recuperación de suelo promovido por entidades públicas en caso de que no sea utilizado para el fin previsto para asegurar el eficaz uso de recursos públicos invertido en la urbanización de ese suelo. Además sería oportuno declarar una moratoria en la urbanización de suelo para actividades económicas y plantearse el tema de la sostenibilidad de un modo más realista. El cierre de empresas y la deslocalización de algunos establecimientos va a dejar suelo ya urbanizado vacante. Vinculado a la deslocalización habría que considerar que la demanda probable en los próximos años sea de menor volumen de metros cuadrados pero de una calidad dotacional muy alta.

- La oferta de suelo industrial, la mejora de accesibilidad por carretera, la dotación de infraestructuras del conocimiento y de transporte, junto al intenso crecimiento económico que ha habido en Álava apoyado en una cimentada política de innovación ha supuesto la atenuación de contrastes socioeconómicos a nivel intraprovincial. Neu- 
tralizar la persistente macrocefalia vitoriana y reforzar la red de núcleos de población restante es un objetivo a seguir impulsando.

\section{BIBLIOGRAFÍA}

ÁLVAREZ, I.-TORRES, M M C. (2008): «El mapa industrial de Álava». XI Coloquio Ibérico de Geografía. A.G.E.-Universidad de Alcalá-A.P.G., Alcalá de Henares.

AAVV (2011): «Proyecto MITKE: impulso a la gestión de las áreas empresariales y polígonos industriales». XXX Cursos de verano UPV-EHU, Donostia-San Sebastián.

BASAGOITI, A. (2008): «El emprendedor, ¿nace o se hace?». Boletín del Círculo de Empresarios Vascos, $\mathrm{n}^{\circ} 61$.

BOE, $n^{\circ} 31$ de 5/2/2008, apartado 1899 Instrumento de Ratificación del Convenio Europeo del Paisaje (número 176 del Consejo de Europa), hecho en Florencia el 20 de octubre de 2000.

BUSQUETS, J. dir. (2007): Guía d'íntegració paisatgistica. Poligons Industrials i sectors d'activitat economica. Generalitat de Catalunya. Disponible en http://www.catpaisatge. net

CARAVACA, I-MÉNDEZ, R. (1996): «Suelo público para la reindustrialización. La actuación de S.E.P.E.S. en la promoción de suelo industrial en España». Ería, no 39-40.

CARAVACA, I. (2011) «El análisis de las áreas empresariales. Diversas miradas a espacios crecientemente complejos» en Áreas empresariales, suelo industrial y logística: análisis y procesos en el territorio (Del Pozo, P. dir.). Navarra: Thomson Reuters-Aranzadi.

COMUNIDAD DE MADRID-TAP (1991): La rehabilitación integral de áreas industriales: un programa de desarrollo económico de la Comunidad de Madrid. Madrid. Dirección General de Economía y Planificación.

DEL POZO, P. (2006) «Promoción y valorización del suelo industrial en Asturias». Boletín de la Asociación de Geógrafos Españoles, nº 42.

ESCALONA, A.I.-CLIMENT, E.,-SÁNCHEZ-VALVERDE, B.- LLANOS, A. (2007): «Influencia de las políticas de suelo sobre la localización de industrias en áreas metropolitanas: el caso de Zaragoza». Scripta Nova, Vol. XI, n 240 . Universidad de Barcelona.

ESTEBAN, M. (1999): Bilbao, luces y sombras del titanio: el proceso de regeneración del Bilbao metropolitano. Leioa. UPV-EHU.

ESTEBAN, M.-UGALDE, M.I.-RODRÍGUEZ, A.-ALTUZARRA, A. eds. (2008): Territorios inteligentes: dimensiones y experiencias internacionales. La Coruña. Netbiblo.

EZQUIAGA, J.M.-NEL-LO, O. (2010) «Los retos de la inclusión de las variables del paisaje en la ordenación territorial y el planeamiento». Ciclo de paisaje: El paisaje ante el cambio global. UPV-EHU, Vitoria-Gasteiz.

FUNDACIÓN ENTORNO (2005): La gestión sostenible en los polígonos industriales. Disponible en http://www.fundacionentorno.org

GARCÍA, J.R.-PUCH, L.A.-GARCÍA, E.-GUTIÉRREZ, L.F. (2011): «Inversión e innovación en el País Vasco: el caso de Álava». Papeles de Economía Española, no 127.

GUAL, J. (2009): «Un largo camino a la recuperación». Boletín $n^{\circ}$ 64, Círculo de Empresarios Vascos. 
GURRUTXAGA, A. (2010): «El sistema de gobernanza en el País Vasco». Ekonomiaz, nº 74.

GONZÁLEZ, B. (2008): «El proceso de planificación y adquisición del suelo». II Encuentro de Promoción y Gestión de Suelo Industrial Proinland 2008. Sprilur, Bilbao.

GUTIÉRREZ PUEBLA, J. (2004): «Producción de suelo industrial en la Comunidad de Madrid: expansión, dispersión y fragmentación del espacio industrial». Anales de Geografía de la Universidad Complutense, $\mathrm{n}^{\circ} 24$.

ITURRATE, J.M. (2011): «Espacios para emprender y competir» en Dinero y Empleo, El Correo, 16/01/2011.

JIMÉNEZ HERRERO, L.M. dir. (2008): Sostenibilidad local: una aproximación urbana y rural. Observatorio de la Sostenibilidad en España.

LAMELAS, M.T. (2009): «Esquema metodológico para la toma de decisiones sobre el uso sostenible del suelo: aplicación a la localización del suelo industrial». Geofocus. Revista Internacional de Ciencia y Tecnología de la Información Geográfica, $\mathrm{n}^{\circ} 9$.

MÉNDEZ, R. (1997): «Los procesos de cambio industrial en la renovación de las políticas de promoción y ordenación» en Actividades productivas y urbanismo. Junta de Andalucía, Consejería de Obras Públicas y Transportes, Sevilla.

MÉNDEZ, R. (2006): «Políticas de promoción y ordenación industrial en las áreas urbanas» en Industria y ciudad en España: nuevas realidades, nuevos retos (Méndez, R.-Pascual, H. edit.). Zizur Menor (Navarra), Thomson-Civitas.

MÉNDEZ, R. dir. (2006): Informe Anual 2006. Observatorio industrial de Madrid. Madrid. Ayuntamiento de Madrid.

MÉNDEZ, R. (2007): «Transformaciones productivas y espacios de actividad en las áreas urbanas: algunas propuestas a debate». II Jornadas de Geografía Económica. Salamanca.

MÉNDEZ, R. coord. (2008): «Madrid: el territorio de las nuevas economías metropolitanas. Algunas claves interpretativas». II Jornadas de Campo de Geografía Económica. Grupo de Geografía Económica, AGE. Madrid.

MÉNDEZ, R. edit. (2010): Estrategias de innovación industrial y desarrollo económico en las ciudades intermedias de España. Madrid. Fundación BBVA.

MÉNDEZ, R.-PASCUAL, H. edit. (2006): Industria y ciudad en España: nuevas realidades, nuevos retos. Navarra. Thomson-Civitas.

MÉNDEZ, R.-RODRÍGUEZ, J. (1991) «Innovación tecnológica y desequilibrios territoriales en España». Estudios Territoriales, 37.

MORA, F. (2006): Nuevas formas de gestión de las áreas empresariales. Asturias. Coordinadora Española de Polígonos Empresariales.

NOGUÉ, J.-GALÁN, J. (2011) «Paisajismo y sostenibilidad territorial». Ciclo de paisaje: $E l$ paisaje ante el cambio global. UPV-EHU, Vitoria-Gasteiz.

OSE (OBSERVATORIO DE LA SOSTENIBILIDAD EN ESPAÑA) (2006): Cambios de ocupación del suelo en España. Implicaciones para la sostenibilidad.

ORQUESTRA (2011): Informe de competitividad del País Vasco 2011. Disponible en http:// www.orquestra.deusto.es

OCDE (2011): Estudios de la OCDE sobre innovación regional: País Vasco, España. OCDE-Innobasque. 
OUGHTON, C.-LANDABASO, M.-MORGAN, K. (2002) «The regional innovation paradox: innovation policy and industrial policy». Journal of technology transfer, 27.

PÉREZ DE LA PEÑA, G. (2008): 1982-2007 Industrialdeak. 25 años de una política de promoción industrial exitosa. Bilbao. Sprilur.

RUIZ, E.-GALDOS, R. (2008): Geografía del País Vasco. San Sebastián. Nerea.

SÁNCHEZ, J.E. (2009): «Barcelona: de ciudad industrial a metrópolis internacional». III Jornadas de Campo de Geografía Económica, AGE, Barcelona.

SPRILUR (2009): Informe anual 2008.

SPRILUR (2010): Guía para el desarrollo sostenible de los proyectos de urbanización. Disponible en http://www.sprilur.es

SPRILUR (2011): Informe anual 2010.

SPRILUR (2009): Guía de Edificación Ambientalmente Sostenible en Edificios industriales en la Comunidad Autónoma del País Vasco. Disponible en http://www.sprilur.es

TORRES, M.C. (1995): Industria y territorio en Bizkaia. IVAP. Vitoria-Gasteiz.

TORRES, C. (1998): «La industria en la C.A.P.V.» en Geografía de Euskal Herria (Meaza, G.-Ruiz, E. dir.). Bilbao. Ostoa-Etor.

TORRES, C.-LAGENDIJK, A. (2000): «Industrial policy in the Basque Country» en Restructuring industry and territory. The experience of Europe's regions. (Giunta, A.- Lagendijk, A.-Pike, A. edit.). London. The Stationery Office.

TARROJA, A.-CAMAGNI, R. coord. (2006): Una nueva cultura del territorio. Criterios sociales y ambientales en las políticas y el gobierno del territorio. Barcelona: Diputació de Barcelona.

UDALPLAN Disponible en http://www.euskadi.net

VÁZQUEZ BARQUERO, A. (2007): «Desarrollo endógeno. Teorías y políticas de desarrollo territorial». Investigaciones Regionales, $\mathrm{n}^{\circ} 11$. 